Egyptian

Orthodontic Journal

\title{
A RADIOGRAPHIC COMPARISON OF APICAL ROOT RESORPTION BETWEEN HERBST AND JUMPER TWIN BLOCK BITE APPLIANCES
}

\author{
Mahasen A Taha ${ }^{1}$, Shaza M Hammad ${ }^{2}$
}

\section{ABSTRACT:}

Objectives: The objectives of this study were to compare the amount of apical root resorption after orthodontic treatment with Herbst and Twin Block. Bite Jumping screw (TBBBS) functional appliances, also to determine the prevalence of root resorption in the maxillary and mandibular incisors and the dental arches.

Methods: 30 patients were divided into two groups 15 patients each. The first group was treated with Herbst appliance and the second group with TBBJS appliance. After treatment, periapical radiographs were obtained of the maxillary and mandibular incisors with the long-cone paralleling technique. Root resorption was scored according to the method of Levander and Malmgren.

Results: Results of the Mann-Whitney $\mathcal{V}$ test showed that there were no statistically significant differences between the Herbst and TBBBS groups. The amounts of root resorption were predominantly small. The prevalence of resorption for the incisors was greatest for the maxillary central, followed by the maxillary lateral, mandibular central, and mandibular lateral incisors.

Conclusions: There was no difference in the amount of root resorption between the Herbst and TBBJS groups with more resorption in maxillary arch than mandibular arch.

1- Lecturer of Orthodontics, Faculty of Dentistry, Mansoura University.

2- Lecturer of Orthodontics, Faculty of Dentistry, Mansoura University. 
Egyptian

Orthodontic Journal

\section{INTRODUCTION}

Apical root resorption is an iatrogenic problem associated with orthodontic treatment. External root resorption is initiated 14-20 days after the application of orthodontic force, and may continue for the duration of force application ${ }^{1}$. In most cases root resorption will be minor and therefore of no clinical importance. However about $4 \%$ of patients experience generalized resorption of more than $3 \mathrm{~mm}$ and about $5 \%$ of adults and $2 \%$ of adolescents are likely to have one or more teeth that undergo more than $5 \mathrm{~mm}$ of resorption during appliance therapy ${ }^{2,3}$.

Root resorption associated with orthodontic treatment, commences adjacent to an area of hyalinization and is more likely to occur in cases where compression is strong and of some duration ${ }^{4,5,6}$. Elimination of hyalinized compressed tissue is carried out by an invasion of cells from adjacent undamaged periodontium. This results in removal of both cementoid and the mature collagen adjacent to the cementum, with subsequent alteration of the normal barriers to root resorption ${ }^{7}$. Once the force application is removed, repair of resorped tooth surface occurs by formed precementum which act as a barrier against further resorption ${ }^{8}$.

Many factors have been implicated in the initiation and progression of external root resorption during orthodontic treatment. These can be divided into local factors and factors related to mechanotherapy ${ }^{3}$. Local factors are: individual susceptibility ${ }^{9}$, stage of root development ${ }^{3,10}$, tooth type $^{11}$, deviating root apex form ${ }^{2,12}$, traumatized teeth ${ }^{3,13,14}$, endodonticaly treated teeth ${ }^{15}$, root apex contact with the cortical plate ${ }^{16,17}$, and adverse habits such as nail biting ${ }^{18}$ and tongue thrust ${ }^{19}$. Mechanical factors are, types of tooth movement $3,20,21,22$, the magnitude of force applied ${ }^{3,11,18,22 \text {, }}$ treatment duration ${ }^{3,11,16,23}$, the use of Class 11 elastics and rectangular wire 3,10 , and certain types of orthodontic appliances ${ }^{24,25,26}$.

Although many studies have been done to compare the effects of removable and fixed appliances on root resorption ${ }^{27-33}$, there is still a debate about the effects of fixed and removable functional appliances on root resorption of maxillary and mandibular incisors.

The primary aim of this study was to compare the amount of root resorption of the upper and lower incisors after treatment with Herbst 
(fixed functional appliance) and Twin Block Bite Jumping Screw (TBBJS) (removable functional appliance) appliances. Also to determine the prevalence of root resorption in the maxillary and mandibular incisors and the dental arches.

\section{MATERIALS AND METHODS}

The sample of this study consisted of thirty female patients treated in Orthodontic Department, Faculty of Dentistry, Mansoura University, with age range 9-11 years (mean age of 10 years 3 months) presenting with Class 11 Division 1 malocclusion due to mandibular retrusion. The inclusion criteria were patients with vital, intact, and caries free incisors. Patients with history of trauma, periapical inflammation, endodontic treatment, root resorption of the incisors prior to orthodontic treatment, dilaceration of the incisors roots, anodontia, or habits were excluded.

The patients were divided into two groups of 15 patients each;

Group 1, patients were treated with banded Herbst appliance*. A telescope mechanism on each side of the jaws was attached to bands on maxillary first molars and mandibular first premolars to keep the mandible in a continuous anterior jumped position. Each telescope consists of a tube and plunger fit together. The tube is attached to the maxillary molar band and the plunger to the mandibular premolar band. The tube and plunger are attached to their respective bands with screws. The length of the tube determines the amount of anterior bite jumping. The length of the plunger is adjusted to the length of the tube. To increase the anchorage, maxillary first premolars were banded and a palatal wire was soldered to molar and premolar bands. In the lower arch, first molars were banded and lingual arch was soldered to them ${ }^{34,35}$. The mean treatment time was 9.8 months.

Group 2, patients were treated with Twin Block Bite Jumping Screw (TBBJS). The same design of Clark ${ }^{36}$ with the addition of bite jumping screw $^{* *}$ to allow gradual advancement of the bite. Bite jumping screw incorporated longitudinally in the upper bite blocks, with the screw head

\footnotetext{
*Dentaurum Group ,Turnstraße 31 ,75228 Ispringen, Germany.

${ }^{* *}$ ForestadentUSA, 2301 Weldon Parkway, St. Louis, MO 63146.
} 
at 70 degree angle to the lower bite blocks. The initial wax bite was taken with the mandible protracted approximately $5 \mathrm{~mm}$ and opened vertically about $4 \mathrm{~mm}$. The bite jumping screw was opened with a special stainless steel key to be active after eight weeks of twin block wear to give $2 \mathrm{~mm}$ advancement of the bite. Then another $2 \mathrm{~mm}$ was obtained by activation of the screw after another eight weeks. If further correction was needed, there was still $2 \mathrm{~mm}$ of advancement left in the system. The mean treatment time was 11.7 months.

To quantify resorption, post treatment periapical radiographs of the maxillary and mandibular incisors, totaling 240 teeth, were examined. The post treatment periapical radiographs were obtained with the DABI 70 Spectro 1070X x-ray machine (Dabi Atlante, Ribeirão Preto, Brazil), set up for $70 \mathrm{kV}, 10 \mathrm{~mA}$, and an exposure time of 1 second, with the longcone paralleling technique. Kodak Ektaspeed EP 21 films (Eastman Kodak, Rochester, NY) were used, and the angles were obtained by an intraoral XCP positioner (Rinn-Dentisply, Elgin, Ill) ${ }^{37}$. All radiographs were processed automatically. All films were scanned, and the images were displayed and analyzed on a large computer monitor at 2-times magnification. Resorption was evaluated by the subjective score system of Levander and Malmgren ${ }^{12}$ (Fig 1,2). The scores were blindly assigned by one examiner.

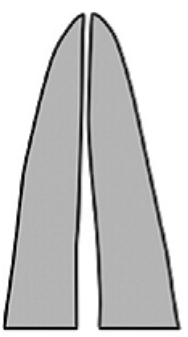

0

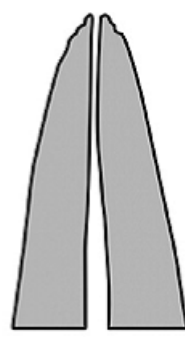

1

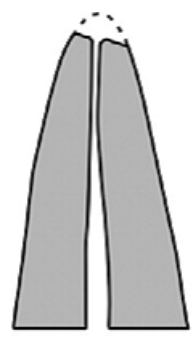

2

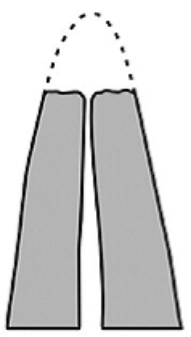

3

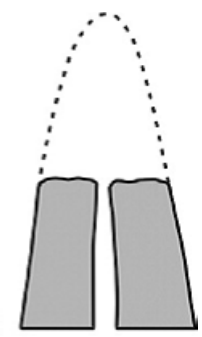

4

Fig.(1): Score system of Levander and Malmgren:

grade 0 , no root resorption; grade 1, mild resorption-root with normal length and only irregular contour; grade 2 , moderate resorption-small area of root loss with apex having almost straight contour; grade 3, accentuated resorption-loss of almost one third of root length; grade 4, extreme resorption-loss of more than one third of root length. 
Fig.(2): Application of the score system on upper central incisors:

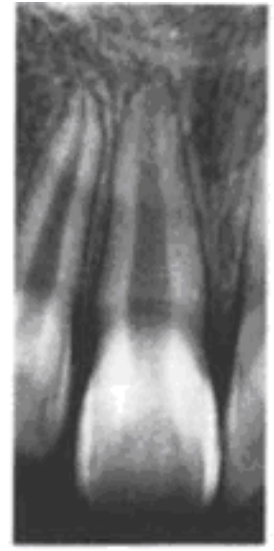

(score 1)

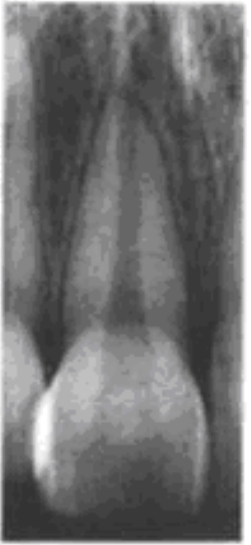

(score 2)

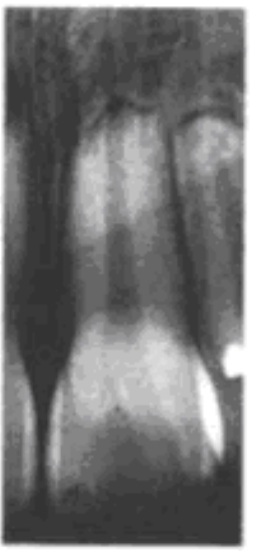

(score 3)

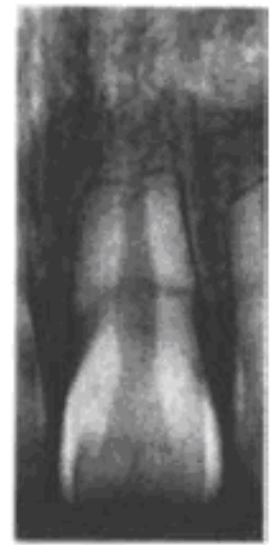

(score 4)

The resorption score was determined for each tooth; there were 8 evaluations per subject. Additionally, a mean resorption score was calculated for each subject. Thereafter, a mean for each group, based on the mean for each subject, was calculated and compared between the groups ${ }^{38}$.

\section{STATISTICAL ANALYSIS}

The comparisons between root resorption in the two groups were performed by means of nonparametric statistics (Mann-Whitney U test) with a social science statistical package (SPSS 10.0, SPSS, Chicago, Ill). Statistical significance was tested at $\mathrm{P}<.05$. Descriptive statistics were used to evaluate the prevalence of root resorption grades in each group and the prevalence of root resorption in the incisors and the dental arches.

\section{RESULTS}

The results revealed that there were no statistical differences in the degree of root resorption between the two groups. The total mean of root resorption in the Herbst group was 1.03 and 1.12 in the TBBJS group 
$(\mathrm{P}=0.76)$, (Table 1). Both groups had a greater prevalence of mild resorption; grade 1 in $70 \%$ of the Herbst group and $72.5 \%$ of the TBBJS group. Extreme apical root resorption was not observed (Table 2).

The prevalence of root resorption was greater in the maxillary arch than in the mandibular arch; $56 \%$ in the maxillary arch in both groups and $40 \%$ and $39 \%$ in the mandibular arch in the Herbst and TBBJS groups respectively. Furthermore, it occurred in decreasing order, maxillary central incisors, maxillary lateral incisors, mandibular central incisors, and mandibular lateral incisors ( Table 3).

Table 1. Comparison of the mean for each tooth and the total mean of each group.

\begin{tabular}{|c|c|c|c|}
\hline & $\begin{array}{c}\text { Group 1 } \\
(\mathbf{n}-\mathbf{1 5})\end{array}$ & $\begin{array}{c}\text { Group2 } \\
\text { (n - 15) }\end{array}$ & P \\
\hline Tooth & $\begin{array}{c}\text { Median } \\
\text { (mean) }\end{array}$ & $\begin{array}{c}\text { Median } \\
\text { (mean) }\end{array}$ & 0.69 \\
\hline 11 & $1.00(1.4)$ & $1.5(1.5)$ & 0.60 \\
\hline 21 & $1.5(1.5)$ & $2.00(1.6)$ & 0.80 \\
\hline 41 & $1.00(0.95)$ & $1.00(1.2)$ & 0.69 \\
\hline 31 & $1.00(0.75)$ & $1.00(0.75)$ & 0.06 \\
\hline 12 & $1.00(1.1)$ & $1.5(1.5)$ & 0.70 \\
\hline 22 & $1.00(1.2)$ & $1.00(1.3)$ & 0.20 \\
\hline 42 & $1.00(0.7)$ & $0.00(0.4)$ & 0.92 \\
\hline 32 & $1.00(0.6)$ & $1.00(0.73)$ & 0.76 \\
\hline Mean & $1.00(1.03)$ & $1.00(1.12)$ & \\
\hline
\end{tabular}

Table 2. Prevalence of root resorption grades in groups.

\begin{tabular}{|l|c|c|c|c|c|c|c|c|c|c|}
\hline \multicolumn{10}{|c|}{ Grade } \\
\hline & \multicolumn{2}{|c|}{ 0 } & \multicolumn{2}{|c|}{1} & \multicolumn{2}{c|}{2} & \multicolumn{2}{c|}{3} & \multicolumn{2}{c|}{4} \\
\hline & Prevalence* & $\%$ & Prevalence & $\%$ & Prevalence & $\%$ & Prevalence & $\%$ & Prevalence & $\%$ \\
\hline Group 1 & $24 / 120$ & 20 & $84 / 120$ & 70 & $12 / 120$ & 10 & $0 / 120$ & 0.00 & $0 / 120$ & 0.00 \\
\hline Group 2 & $25 / 120$ & 20.8 & $87 / 120$ & 72.5 & $8 / 120$ & 6.66 & $0 / 120$ & 0.00 & $0 / 120$ & 0.00 \\
\hline
\end{tabular}

*Number of resorped roots/number of examined roots. 
Table 3. Prevalence of root resorption in incisors and dental arches.

\begin{tabular}{|c|c|c|c|c|}
\hline & \multicolumn{2}{|c|}{$\begin{array}{c}\text { Group 1 } \\
\text { Group 2 } \\
\text { (n - 15) }\end{array}$} & Prev & \% \\
\hline Teeth & Prev* & \% & $26 / 120$ & 21.6 \\
\hline 12,22 & $27 / 120$ & 22.5 & $30 / 120$ & 25.0 \\
\hline 11,21 & $29 / 120$ & 24.2 & $15 / 120$ & 12.5 \\
\hline 32,42 & $17 / 120$ & 14.2 & $24 / 120$ & 20 \\
\hline 31,41 & $23 / 120$ & 19.1 & $56 / 120$ & 46.6 \\
\hline Max arch & $56 / 120$ & 46.6 & $39 / 120$ & 32.5 \\
\hline Mand arch & $40 / 120$ & 33.3 & $95 / 120$ & 79.1 \\
\hline Total & $96 / 120$ & 79.9 & & \\
\hline
\end{tabular}

*Number of resorped roots/number of examined roots.

Prev, prevalence; Max, maxilla; Mand, mandible 12, Maxillary right lateral incisor; 11, maxillary right central incisor; 21, maxillary left central incisor; 22, maxillary left lateral incisor; 42, mandibular right lateral incisor; 41, mandibular right central incisor; 31, mandibular left central incisor; 32, mandibular left lateral incisor.

\section{DISCUSSION}

The selection of periapical paralleling technique in evaluating the degree of apical root resorption in this study was based on the fact that it provides the most appropriate information with the lowest irradiation to the patient when used for teeth that are most likely to exhibit blunting of roots "maxillary and mandibular incisors" ${ }^{39}$. It also provides less distortion and superimposition errors compared with orthopantomogram or the lateral head film and up to 4 films enable absorption of lower doses by radiosensitive tissue of the head and neck.

The most sensitive teeth to root resorption are the maxillary and mandibular incisors ${ }^{9,20,40,41,42}$. It is believed that if there is no apical root resorption seen in the incisors, then significant apical resorption in the other teeth is less likely to occur ${ }^{16,42,43}$. So, the aim of this study was to focus on the amount of root resorption in these teeth. 
In this study, the amount of resorption was predominantly small. This may be explained by the young age of the patients (10 years and 3 months). Where, there is a higher susceptibility to root resorption seen in the adults ${ }^{14}$. All tissues involved in the root resorption process have changes with the age. The periodontal membrane becomes less vascular, aplastic and narrow, the bone more dense, avascular ,and aplastic, and the cementum wider. These changes are reflected by higher susceptibility to root resorption in the adults. Only few studies showed no relationship between the apical root resorption and age of the patient ${ }^{9,20}$. Also the short duration of treatment may be a factor (9.8 months in Herbst and 11.7 months in TBBJS). Most studies reported that the severity of root resorption is directly related to treatment duration ${ }^{11,12,44,45}$. One study ${ }^{45}$ reported that the amount of root loss during treatment is $0.9 \mathrm{~mm} /$ year. Other study ${ }^{44}$ reported that $40 \%, 70 \%, 80 \%$ and $100 \%$ of patients in treatment demonstrated some root resorption after 1,2,3, and 7 years of active treatment respectively. Only a few studies did not support this finding 46,47 .

There was no significant difference in apical root resorption between the two appliance systems. This was in conflict with only one study which compared root resorption resulting from fixed and removable appliances ${ }^{3}$, concluding that the use of fixed appliance is more detrimental to the roots. Where normal function of the teeth is disturbed by the splinting effect of orthodontic fixed appliances over a long period. The pause in treatment with intermittent forces of the removable appliances allows the resorped cementum to heal and prevent further resorption. On the other hand another studies ${ }^{3,48}$ found that the intermittent forces have been linked in their detrimental effects to jiggling forces which are more harmful to the roots. However, in this study the treatment period was not long. Also, there were not any fixed appliances used directly on the incisors with Herbst appliance.

As in other studies ${ }^{8,47,49,50}$, there was greater root resorption in the maxillary teeth in the two groups than in the mandibular teeth. Where root resorption is directly related to the distance moved by the roots ${ }^{11,21,22,48,51}$. The extent of movement in these teeth is usually greater than in other teeth because of malocclusion function and esthetics. The root structures 
and relationship to bone and periodontal membrane tend to transfer the forces mainly to the apex ${ }^{52}$. Therefore it is not surprising to detect greater apical root resorption in these teeth. In this study there was a greater resorption in the upper central incisors than the lateral incisors. This finding was also reported in other literatures ${ }^{5,53,54,55}$ which is in a decreasing order, maxillary central, maxillary lateral, mandibular central, and mandibular lateral incisors. On the other hand, other studies found that, the most frequently affected teeth are maxillary laterals, maxillary centrals then mandibular incisors. The results of our study can be attributed to the age of our sample (mean age: 10 years and 3 months), where the roots of the upper lateral incisors were not completely formed by this age, the maxillary lateral incisors are the last incisors to complete root formation at 11 years of age ${ }^{3,56}$. The teeth with incompletely formed roots have greater resistance to resorption than teeth with completely formed roots 57 .

\section{CONCLUSIONS}

Both Herbst appliances and TBBJS caused apical root resorption. However, the amounts of root resorption were predominantly small with no significant difference between the two appliances.

The prevalence of resorption for each incisor group in decreasing order was maxillary central incisors, maxillary lateral incisors, mandibular central incisors, and mandibular lateral incisors.

\section{REFERENCES}

1-Blacke $\mathrm{M}$, Woodside $\mathrm{D} \mathrm{J}$, and Pharoah $\mathrm{M} \mathrm{J}$ : A radiographic comparison of apical root resorption after orthodontic treatment with the edgewise and Speed appliance. Am J Orthod Dentofac Orthop 1995;108:76-84.

2-Mirabella AD, Artun J: Prevalence and 8severity of apical root resorption of maxillary anterior teeth in adult orthodontic patients. Eur J Orthod 1995;17:93-99.

3-Linge BO, Linge L: Apical root resorption in upper anterior teeth. Eur J Orthod 1983;5:173-183.

4-Reitan K: Initial tissue behavior during apical root resorption. Angle Orthod 1974;44:68-82. 
Egyptian

Orthodontic Journal

5-Williams S: A histomorphometric study of orthodontically induced root resorption. Eur J Orthod 1984;6:35-47.

6-Engstorm C, Granstorm G, Thilander B: Effect of orthodontic force on periodontal tissue metabolism: a histological and biochemical study in normal and hypocalcemic young rats. Am J Orthod Dentofacial Orthop 1988;93:468-95.

7-Rygh P: Elimination of hyalinized periodontal tissue associated with orthodontic tooth movement. Scand J Dent Res 1974;82:53-73.

8-Rygh P: Orthodontic root resorption studies by electron microscopy. Angle Orthod 1977;47:1-16.

9-Massler M, Malone AJ: Root resorption in human permanent teeth. Am J Orthod 1954;40:619-33.

10-Linge L, Linge BO: Patient characteristics and treatment variables associated with apical root resorption during orthodontic treatment. Am J Orthod Dentofacial Orthop 1991;99:35-43.

11-Sharp W, Reed P, Subtelny JD, Polson A: Orthodontic relapse, apical root resorption, and crestal alveolar bone levels. Am J Orthod Dentofacial Orthop 1987;91:252-258 .

12- Levander E, Malmgren O: Evaluation of the risk of root resorption during orthodontic treatment: a study of upper incisors. Eur J Orthod 1988;10:30-38.

13-Andreasen JO: External root resorption: its implication in dental traumatology, paedodontics, periodontics, orthodontics, and endodontics. Int Endodont J 1985;18:109-118.

14-Brin I, Ben BY, Heling I, Engleberg A: The influence of orthodontic treatment on previously traumatized permanent incisors. Eur J Orthod 1991;13:373-381.

15-Spurrier SW, Hall SH, Joondeph DR, Shapiro PA, Riedel RA: A comparison of apical root resorption during orthodontic treatment in endodontically treated and vital teeth. Am J Orthod Dentofacial Orthop 1990;97:130-134. 
16- Goldson L, Henrikson C: Root resorption during Begg treatment: a longitudinal roentogenologic study . Am J Orthod 1975;68:55-66.

17- Handelman CS: The anterior alveolus: its importance in limiting orthodontic treatment and its influence on the occurrence of iatrogenic sequelae. Angle Orthod 1996;66:95-110.

18- Odenrick L, Brattstrom V: Nail biting: frequency and association with root resorption during orthodontic treatment. Br J Orthod 1985;12:78-81.

19-Newman WG: Possible etiologic factors in external root resorption. Am J Orthod 1975;67:522-539.

20-McFadden WM, Engstrom C, Engstrom H, Anholm JM: A study of the relationship between incisor intrusion and root shortening. Am J Orthod Dentofacial Orthop1989;96:390-396.

21-Vonder Ahe G: posttreatment status of maxillary incisors with root -end resorption. Angle Orthod1973;43:225-247.

22-Dermaut LR, De MA: Apical root resorption of upper incisors caused by intrusive tooth movement: a radiographic study. Am J Orthod Dentofac Orthop 1986;90:321-326.

23-Reitan K: Initial tissue behavior during apical root resorption. Angle Orthod 1974;44:68-82.

24-Malmgren O, Omblus J: Treatment with an orthopedic appliance system. Eur J Orthod 1985;7:205-214.

25-Beck BW, Hariss EF: Apical root resorption in orthodontically treated subjects: analysis of edgewise and light wire mechanics. Am J Orthod Dentofacial Orthop 1994;105:350-361.

26-Hall AM: Upper incisor root resorption during stage II of the Begg technique: two case reports. Br J Orthod 1978;5:47-50.

27-Brezniak N, Wassertstein A: Root resorption after orthodontic treatment: part II Literature review . Am J Orthod Dentofacial Orthop 1993;103:138-46.

28-Hogberg M, Rosenqvist L: Root resorption following activator treatment. Odontol Foren Tidskr 1974;38:185-192. 
29-Mosling MS, Fogle LL, Gloeckner-Demro J, Bigelow HF: Non extraction treatment of a Class II, Division 1 malocclusion with headgear and functional appliances. Am J Orthod Dentofacial Orthop 1997;112:372-377.

30-Acar A, Canyurek Ü, Kocaaga M: Continuous versus discontinuous force application and root resorption. Angle Orthod 1999;69:159-163.

31-Apajalahti S, Peltola JS: Apical root resorption after orthodontic treatment- a retrospective study. Eur J Orthod 2007; 29:408-412.

32-Sameshima GT, Sinclair PM: Predicting and preventing root resorption: part1. Diagnostic factors. Am J Orthod Dentofacial Orthop.2001;119:505-510.

33-Årtun J, Smale I, Behbehani F, Doppel D, Van't Hof M, Kuijpers-Jagtman AM: Apical root resorption 6 and 12 months after initiation of fixed orthodontic appliance therapy. Angle Orthod 2005;75:919-926.

34-Pancherz H: Treatment of Class II malocclusion by jumping the bite with the Herbst appliance : a cephalometric investigation. Am J Orthod $1979 ; 76: 423-442$.

35-Pancherz H: The nature of Class II relapse after Herbst appliance treatment: a cephalometric long term investigation. Am J Othod Dentofacial Orthop 1991;100:120-233.

36-Clark WJ: The twin block technique: a functional orthopedic appliance system. Am J Orthod 1988;26:9-13.

37- Rinn Corporation: Utilization of the extension cone paralleling, bisecting angle and interproximal techniques with Rinn instruments Elgin, Ill: Rinn Corporation; 1975.

38-Remington DN, Joondeph DR, Artun J, Riedel RA, Chapko MK: The long term evaluation of root resorption occurring during orthodontic treatment. Am J Orthod Dentofacial Orthop 1989;96:43-46.

39-McNicol A,Stirrups DR: Radiation dose during the dental radiographic techniques most frequently used during orthodontic treatment. Eur J Orthod. 1985;7:163-171. 
40-Ketcham AH: A preliminary report of an investigation of apical root resorption of vital permanent teeth. Int J Orthod 1927; 13:97-127.

41-Dougherty HL: The effect of mechanical forces upon the mandibular buccal segments during orthodontic treatment. Am J Orthod 1968;54:83-103.

42-Sjolien T, Zachrison BU: Periodontal bone support and tooth length in orthodontically treated and untreated persons. Aust J Orthod 1973;64:28-37.

43-DeShields RW: A study of root resorption in treated Class II Division 1 malocclusion. Angle Orthod. 1969;39:231-245.

44- Rudolph CE: A comparative study in root resorption in permanent teeth. Am J Dent Assoc 1936;23:822-826.

45-Goldin B: Labial root torque: effect on the maxilla and incisors root apex. Am J Orthod Dentofacial Orthop.1989;95:209-219.

46-Negan PW, Crock B, Vrghese J, Lanese R, Shanfeld J, Davidovitch Z: Immunohistochemical assessment of the effect of chemical and mechanical stimuli on cAMp and postglandin E levels in human gingival fibroblasts in vitro. Arch Oral Biol 1988;33(3):63-74.

47-Kvam E: Scanning electron microscopy of tissue changes on the pressure surface of human premolars following tooth movement. Scand J Dent Res 1972;80:368-375.

48-Stuteville $\mathrm{OH}$ : Injuries of teeth and supporting structure caused by various orthodontic appliances, and methods of preventing these injuries. J Amr Dent Assoc1973;74:435-443.

49-Sodek J, Overall CM: Matrix degradation in hard and soft connective tissue. In: Davidovitch Z, ed Biological mechanisms of tooth root resorption and eruption. 1988:303-312.

50- Nicolay O, Mavee J, Shanfeld J, Davidovitch Z: SP immunoreactivity in dental pulp and periodontium during tooth movement. J Dent Res 1988;67:301, abst. 957. 
51-Hollender L, Ronneman A, Thilander B: Root resorption, marginal bone support and clinical crown length in orthodontically treated patients. Eur J Orthod 1980;2:197-205.

52-Oppenheim A: Biologic orthodontic therapy and reality: part III. Angle Orthod 1936;6:69-112.

53-Lindskog S, Blomlof L, Hammarstrom L: Dentin resorption in replanted monkey incisors. J Clin Periodontol 1988;15:365-370.

54-Takahashi N, Tukita T, Macdonald BR: Osteoclast-like cells form in long term human bone marrow but not in peripheral blood cultures. J Clin Invest 1989;83:543-550.

55-Andreasen JO: Summary of root resorption . In: Davidovitch Z, ed. Biological mechanisms of tooth eruption and root resorption. 1988:399-401.

56-Logan WHG, Kronfeld R: Development of the human jaws and surrounding structures from birth to the age of fifteen years. J Am Dent Assoc 1933;20:372-427.

57-Hendrix I, Carels C, Kuijpers-Jagtman AM, Van T Hof M: A radiographic study of posterior apical root resorption in orthodontic patients. Am J Orthod Dentofacial Orthop 1994, 105:345-349. 